\title{
Advancement of fermentable sugars from fresh elephant ear plant weed for efficient bioethanol production
}

\author{
Marlen Trejo ${ }^{1,2} \cdot$ Prakash Bhuyar $^{1,2} \cdot$ Yuwalee Unpaprom ${ }^{2,3} \cdot$ Natthawud Dussadee $^{1}$. \\ Rameshprabu Ramaraj ${ }^{1,2}$ (D)
}

Received: 8 July 2021 / Accepted: 9 August 2021 / Published online: 17 August 2021

(C) The Author(s), under exclusive licence to Springer Nature B.V. 2021

\begin{abstract}
Bioethanol is considered one of the most promising next-generation automotive fuels, as it is carbon neutral and can be produced from renewable resources, like lignocellulosic materials. The present research investigation aimed to utilize the elephant ear plant, a hazardous plant (weed) also considered an invasive species, as a font of non-edible lignocellulosic biomass for bioethanol production. The freshly collected elephant ear plant (leaves and stalk) was chopped into small pieces $(1-2 \mathrm{~cm})$ and then homogenized to a paste using a mechanical grinder. The sample pretreatment was done by flying ash for three different time durations $(T 1=0 \mathrm{~min}, T 2=15 \mathrm{~min}$, and $T 3=30 \mathrm{~min})$ with 3 replications. All treatment samples were measured for total sugar and reducing sugar content. The concentration of reducing sugar archived was $T 1=0.771 \pm 0.1 \mathrm{mg} / \mathrm{mL}, T 2=0.907 \pm 0.032 \mathrm{mg} / \mathrm{mL}$, and $T 3=0.895 \pm 0.039 \mathrm{mg} / \mathrm{mL}$, respectively. The results revealed that the chemical composition was different among treatments. The hydrolysis was performed using cellulase enzymes at $35{ }^{\circ} \mathrm{C}$ for the hydrolysis process. The hydrolysate was inoculated with $1 \%$ of S. cerevisiae and maintained at room temperature without oxygen for $120 \mathrm{~h}$. Bioethanol concentration was measured by using an ebulliometer. The efficient ethanol percentage was $1.052 \pm 0.03 \mathrm{mg} / \mathrm{mL}$ achieved after the fermentation. Therefore, the elephant ear plant invasive weed could be an efficient feedstock plant for future bioethanol production.
\end{abstract}

Keywords Elephant ear plant $\cdot$ Total sugar $\cdot$ Reducing sugar $\cdot$ Hydrolysis $\cdot$ Fermentation

\section{Introduction}

Globally, derived fossil fuels are the primary energy source, especially in the transportation sector (Bhuyar et al., 2021; Ramaraj et al., 2021a, b). Consequently, the greenhouse gases released into the atmosphere have increased 1.4 per cent per year on average, according

Rameshprabu Ramaraj

rameshprabu@mju.ac.th; rrameshprabu@gmail.com

1 School of Renewable Energy, Maejo University, Chiang Mai 50290, Thailand

2 Sustainable Resources and Sustainable Engineering Research Lab, Maejo University, Chiang Mai 50290, Thailand

3 Program in Biotechnology, Faculty of Science, Maejo University, Chiang Mai 50290, Thailand 
to the UNEP (United Nations, 2020), contributing to environmental pollution and global warming. Therefore, the search for new energy alternatives, environmentally friendly and derived from renewable sources, has become crucial. New technologies for social-economical interactions and rapid urbanization, and industrial expansion make energy vital in the daily life of all people (Cruz et al., 2018). The world economy is heavily dependent on fossil fuels such as oil, coal, natural gas, primary commercial energy, and non-renewable sources (Ramaraj et al., 2016). The worldwide consumption of fossil fuels intensified greenhouse gas emissions released to the atmosphere and all the climate changes promoted by global warming (Dussadee et al., 2014; Ramaraj \& Dussadee, 2015). In this context, biofuels are an emerging alternative to liquid fuels due to their high energy content and significantly less $\mathrm{CO}_{2}$ emissions associated with their use (Dussadee et al., 2016). Bioethanol is a potential alternative fuel due to its properties in comparison with gasoline, such as higher flame speed, higher heats of vaporization, and higher-octane number, which makes it an antiknock fuel, are some of the main reasons to encourage its production (Gavahian et al., 2019; Vu et al., 2017).

According to the International Energy Agency (IEA), in 2019, globally fuel ethanol production reached 115 billion L. However, the COVID-19 crisis causes global bioethanol production to drop $15 \%$ in 2020 , the first contraction in biofuel output in two decades. Despite the fact that biofuels are predicted to meet around $5.4 \%$ of road transport energy demand in 2025, and it was up from just under $4.8 \%$ in 2019. Bioethanol output is expected to reach 119 billion liters in 2023-25, with Brazil, China, and India serving as key growth areas (IEA, 2019). Meanwhile, in Thailand, conventional Thai power generation starts giving alternative sources with the cost reduction of variable energy. As a result, during 2023-25, the average bioethanol yearly production in Thailand of 2.4 billion litres is expected.

Bioethanol can be produced from several different biomass sources (Manmai et al., 2019, 2020a, b; Nguyen et al., 2020). The first biofuel produced from food-based crops, or first-generation bioethanol, involves feedstocks like sucrose from sugarcane in Brazil or starch, mainly from corn, in the USA (Duden et al., 2021; Kumar, 2011). However, even though first-generation bioethanol is being produced commercially in several countries, edible biomass encountered resistance due to the limited stock and the food versus fuel argument. Therefore, there has been a great effort in exploring alternatives feedstocks for second-generation bioethanol production based on lignocellulosic biomass. Lignocellulosic biomass is usually referred to as non-edible crops, agriculture, forestry residues, aquatic plants, and it is considered one of the most abundant renewable biomass sources on earth (Bhuyar et al., 2020; Khammee et al., 2021). The complex and recalcitrant structure of lignocellulosic biomass comprises cellulose, hemicellulose, and lignin, including water in small amounts and some trace amounts of protein, minerals, and other components of raw material (Khammee et al., 2019; Nong et al., 2020; Unpaprom et al., 2021; Van Tran et al., 2020). Lignocellulosic biomass is usually referred to as non-edible crops, agriculture and forestry residues, aquatic plants, and it is considered one of the most abundant renewable biomass sources on earth (Phukoetphim et al., 2017; Ramaraj et al., 2021a, b; Sharma et al., 2020).

The Araceae family of plants, which contains over 1800 know species, has been described as the most common cause of symptomatic plant ingestion in some countries (Atkins \& Williamson, 2008). Most species in the family contain raphine (calcium oxalate) crystals which are needle-shaped and arranged in compact bundles (Frohne \& Pfänder, 1997; Krenzelok \& Jacobsen, 1997). Upon chewing of the plant, the crystals are ejected from specialized explosive ejector cells (idioblasts). As a result, they may become lodged 
in the lining of the mouth, tongue, and throat leading to local inflammatory reactions, including burning, irritation, and oedema of the buccal cavity, hypersalivation, and aphonia (Kuballa et al., 1981; Wiese et al., 1996). The elephant ear plant, a member of the Arum family (Araceae), is a tuberous, stemless, frost-tender aquatic and semi-aquatic herbaceous species. The plant is a perennial capable of producing considerable $(60 \mathrm{~cm}$ length and $35 \mathrm{~cm}$ width) leaves on 1-2.5 m petioles (Weber, 2017) that emanate from a good corm. Under ideal growing conditions, a single elephant ear plant can grow $2.4 \mathrm{~m}$ tall with a similar spread in width. Reproduction of the elephant ear is primarily vegetative, rarely by seed, and occurs when whole corms divide in winter or early spring (Atkins \& Williamson, 2008; Kikuta et al., 1938). Thus, only a portion of the crown and petiole is needed to establish a new plant. The invasive weed utilization for bioenergy generation is the novel approach towards renewable energy. The present investigation aimed to use the elephant ear plant, a hazardous plant also considered an invasive species, as a font of non-edible lignocellulosic biomass for bioethanol production. The bioethanol production was done, followed by pretreatment and hydrolysis techniques. The alcohol determination was done by ebulliometer.

\section{Materials and methods}

\subsection{Plant collection and sample preparation}

The elephant ear plant is a common weed that grows near the water bodies like canals, lakes, puddles, and rivers. Samples of elephant ear plants were collected from Maejo University located at Sansai-Phrao Road, Nongharn, Sansai District, Chiang Mai, 50,290 Thailand, and transferred to the Faculty of Science's laboratory. Collected samples (leaves and kernel) were washed with tap water to remove impurities and chopped into small pieces $(1-2 \mathrm{~cm})$ and then homogenized to a paste using a mechanical grinder (PHILIPS Blender 600 W Model HR2118/02).

\subsection{Pretreatment and hydrolysis}

In the pretreatment step, a total of $50 \mathrm{~g}$ of the homogenized fresh elephant ear plant was taken in a $1000 \mathrm{~mL}$ graduated bottle mixed with $500 \mathrm{~mL}$ of distiller water; this mixture was undergone autoclaving apparatus at $121{ }^{\circ} \mathrm{C}, 15 \mathrm{psi}$, at different time durations $(T 1=0 \mathrm{~min}$, $T 2=15 \mathrm{~min}$, and $T 3=30 \mathrm{~min}$ ). After pretreatment, the $\mathrm{pH}$ of the combined solution was adjusted at $5.0 \pm 0.3$, and the samples were inoculated with $1 \%$ commercial cellulase (Union Science, Pvt. Ltd., Chiang Mai, Thailand) for the hydrolysis process. Afterwards, the solution was kept in an incubator at $35{ }^{\circ} \mathrm{C}$ for $24 \mathrm{~h}$ to perform the hydrolysis. Figure 1 shows the elephant ear plant (leaves and stalk) collected and homogenized and the mixture before and after the hydrolysis step.

\subsection{Fermentation}

After physicochemical hydrolysis, fermentation was performed. The fermentation protocol was followed as described by Khammee et al. (2020). The $\mathrm{pH}$ of the hydrolysate solution was adjusted at $5.6 \pm 0.3$ before being inoculated with $1 \%$ (wt./v) of Saccharomyces 
(a)

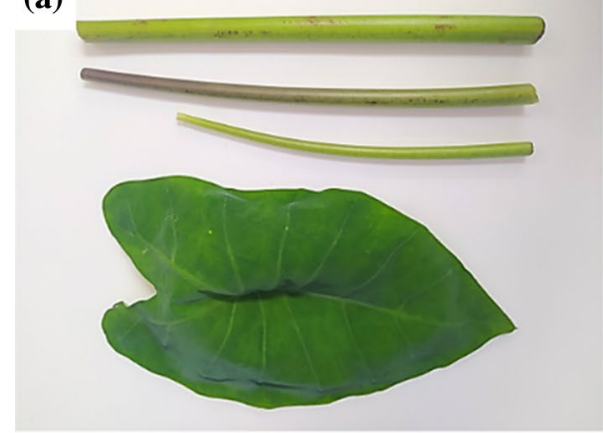

(c)

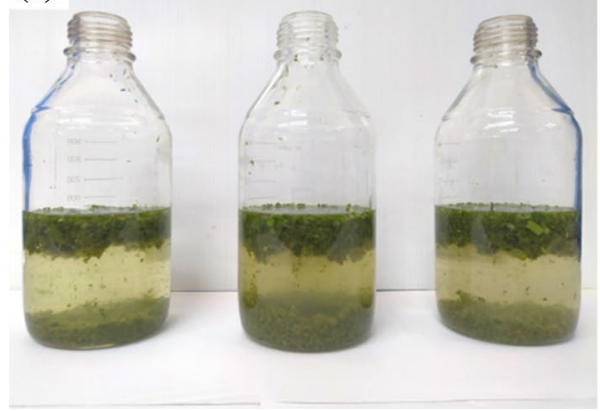

(b)

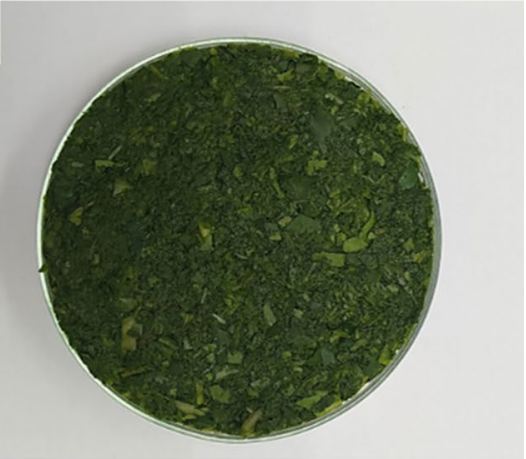

(d)

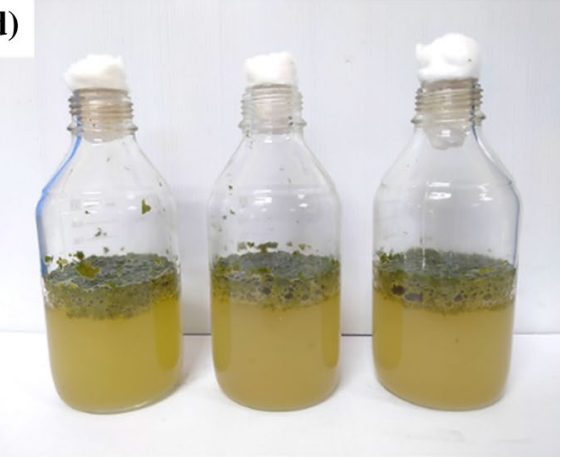

Fig. 1 a Elephant ear plant collected, $\mathbf{b}$ elephant ear plant homogenized and $\mathbf{c}$ mixed with water to proceed with the pretreatment, and $\mathbf{d}$ mixture after hydrolysis process

cerevisiae. The fermented mixture was kept at room temperature in the absence of oxygen for $120 \mathrm{~h}$. The fermentation was carried out for 5 days and monitored by withdrawing $80 \mathrm{~mL}$ of the sample every $24 \mathrm{~h}$ for sugars and alcohol measurement. The alcohol measurement was carried out by using an ebulliometer.

\subsection{Total and reducing sugar assay}

A UV-Spectrophotometer detector DV-8000 (Drawell, Osaka, Japan) was used to estimate sugars concentration through spectrometry. Total sugars and reducing sugars were determined by the phenol sulfuric acid method and the dinitrosalicylic acid (DNS) method (Dubois et al., 1956; Miller, 1959; Saengsawang et al., 2020). For total sugar determination, $500 \mu \mathrm{L}$ of phenol solution $(5 \% \mathrm{w} / \mathrm{v})$ was added to $500 \mu \mathrm{L}$ of the sample. The mixture was homogenized and followed by the addition of $2.5 \mathrm{~mL}$ of the con. sulfuric acid $\left(\mathrm{H}_{2} \mathrm{SO}_{4}\right.$ at $98 \%$ ). The sample was submerged in water for $10 \mathrm{~min}$ and then homogenized using a vortex, and the absorbance was read at $540 \mathrm{~nm}$ using distilled water as control. Meanwhile, $500 \mu \mathrm{L}$ of DNS reagent was added to $500 \mu \mathrm{L}$ of the sample for reducing sugars. The mixture was put in a boiling water bath for $10 \mathrm{~min}$. Then, it was cooled, and $4 \mathrm{~mL}$ of distiller water was added. The absorbance was read at $540 \mathrm{~nm}$ using distilled water as control. All the procedures for reducing sugars determination were done under dark conditions due to the photosensitive nature of the DNS reagent. For both total sugars and reducing sugars, a 
standard curve was generated using standard D-Glucose solution to derive the concentration of an unknown sample in $\mathrm{mg} / \mathrm{mL}$.

\subsection{Alcohol determination}

Ethanol content measurement was carried out using an ebulliometer (Dujardin-Salleron, Alcohol Burner, France). Ebulliometer is based on the principle that the boiling point of an alcoholic mixture is depressed compared to the boiling point of water due to the alcohol content in the alcoholic mixture (Olson, 1989). Alcohol analysis was performed by using the ebulliometer chamber which was filled with $50 \mathrm{~mL}$ of sample and boiled until a steady temperature. The resulting distiller water boiling point was used to compare the ebulliometer disc provided with the apparatus.

\subsection{Statistical analysis}

Statistical analysis was performed using Statgraphics Centurion 19. For the present study, three replicates for all experiments were conducted. Data were shown as mean $\pm S E$ from triplicate. A significant difference was examined at the level of $p<0.05$.

\section{Results and discussion}

\subsection{Physical pretreatment and enzymatic hydrolysis}

In this study, hydrothermal and steam explosion pretreatment to fresh elephant ear plants was investigated for three different time durations $(T 1=0 \mathrm{~min}, T 2=15 \mathrm{~min}$, and $T 3=30 \mathrm{~min}$ ). The pretreatment with the highest total sugar concentration was selected to perform the hydrolysis step. The hydrolysis process converts total sugars to reducing (fermentable) sugar by breaking the polysaccharides into monosaccharides. The highest fermentable sugar content sample was utilized for the fermentation process. Samples were analyzed before and after the pretreatment and hydrolysis step to study the changes in total sugar and reduce sugar $(\mathrm{mg} / \mathrm{mL})$. Figure 2 representing the pictorial representation of the pretreatment process.

Figures $3 \mathrm{a}$ and $\mathrm{b}$ displayed total sugar results and reduced sugar at three different time durations. The concentration of reducing sugar archived was $T 1=0.771 \pm 0.1 \mathrm{mg}$ / $\mathrm{mL}, T 2=0.907 \pm 0.032 \mathrm{mg} / \mathrm{mL}$, and $T 3=0.895 \pm 0.039 \mathrm{mg} / \mathrm{mL}$, respectively. Meanwhile, the concentration of fermentable sugar after enzyme hydrolysis procedure was $T 1=0.838 \pm 0.033 \mathrm{mg} / \mathrm{mL}, T 2=1.130 \pm 0.042 \mathrm{mg} / \mathrm{mL}, T 3=1.067 \pm 0.013 \mathrm{mg} / \mathrm{mL}$ as shows Fig. 2. $T 2$ presented the highest concentration of reducing sugars compared with $T 1$ and $T 3$.

Results revealed that the pretreatment of 15 min steam explosion results in higher fermentable sugars. Therefore, the $T 2$ condition was selected to perform the fermentation procedure. Table 1 illustrating the literature survey of various plant weeds utilized for bioethanol production with different pretreatment and hydrolysis protocols. It was reported that after dilute acid pretreatment, hemicellulose disintegrates, and xylose is released into solution, whereas alkaline pretreatment preserves a portion of hemicellulose while removing most of the lignin component (Aswathy et al., 2010; Lin et al., 2016). The combination microbial-chemical method could significantly boost the generation of reducing sugars in 


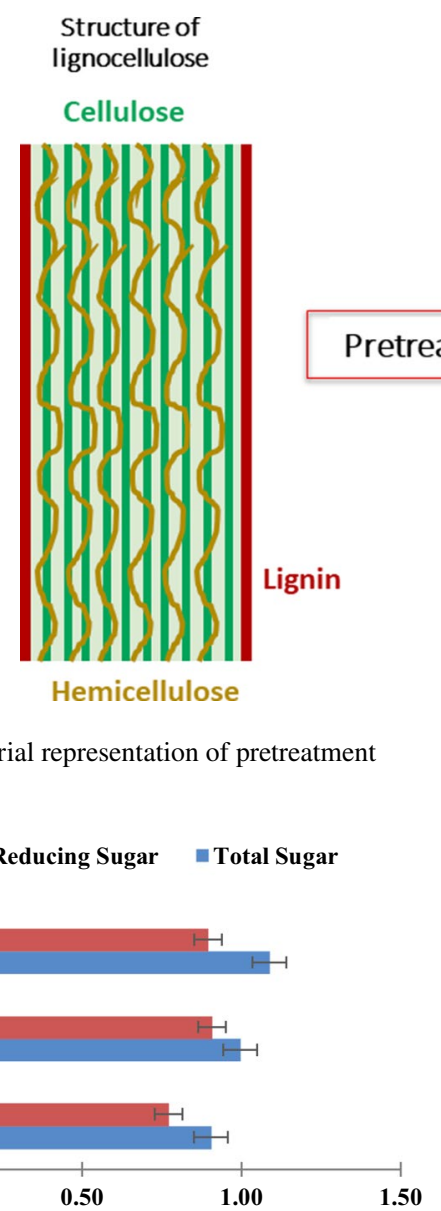

0.00
0.50

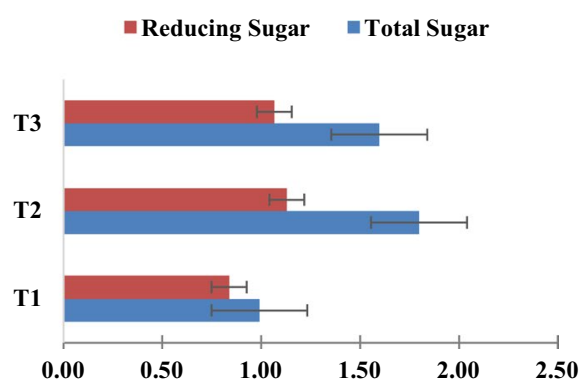

(b) Hydrolysis Sugar Conc. $(\mathrm{mg} / \mathrm{mL})$

Fig. 3 The concentration of sugar at three different pretreatment times and after the enzyme hydrolysis step a pretreatment and $\mathbf{b}$ after hydrolysis

water hyacinth hydrolysates compared to a single MB method (Zhang et al., 2018). However, as with other cellulosic bioethanol feedstocks, such as herbaceous grasses and agriculture or forestry residues, aquatic and semi-aquatic plants require a pretreatment step, followed by a hydrolysis and fermentation process as a general method for bioethanol production (Isarankura-Na-Ayudhya et al., 2007; Taherzadeh \& Karimi, 2008; Whangchai et al., 2021).

\subsection{Bioethanol production}

The hydrolysate mixture obtained from $\mathrm{T} 2$ was undergone a fermentation process using $1 \%$ wt./v of $S$. cerevisiae (dry yeast). The bioethanol production was monitored for 5 days at room temperature, and a sample was withdrawn each $24 \mathrm{~h}$ to record the bioethanol concentration. Results are shown in Fig. 4. After $48 \mathrm{~h}$, the fermentable sugars were 


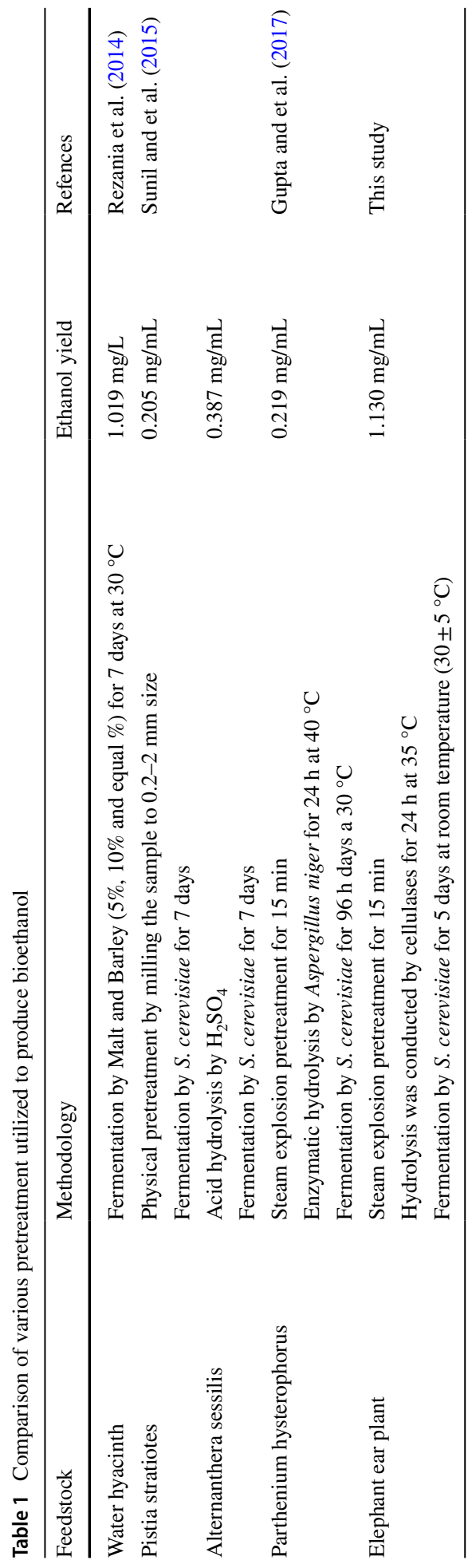




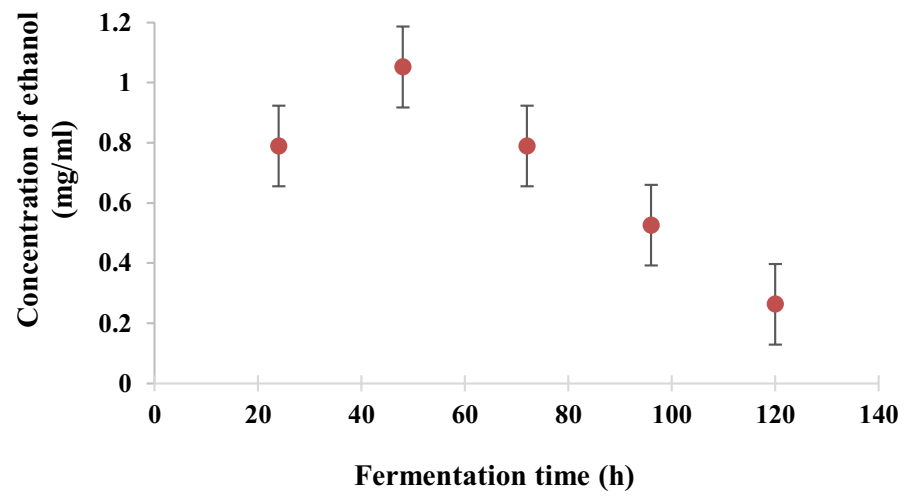

Fig. 4 Bioethanol production from fresh elephant ear plant from $120 \mathrm{~h}$

recorded as $0.826 \pm 0.02$, at which the highest bioethanol concentration was reached at $1.052 \pm 0.03 \mathrm{mg} / \mathrm{mL}$. As the sugars were exhausted gradually, the ethanol production was reduced, as displayed in Fig. 4.

The fermenting microorganisms play an essential role in bioethanol production from lignocellulosic biomasses by fermenting a wide range of sugars to ethanol (Dien et al., 2003). Compared to other types of microorganisms, yeast is the most common microbe employed in ethanol production. S. cerevisiae is the widely used fermenting yeast due to its high ethanol productivity, high ethanol tolerance, and the ability to ferment a wide range of sugars (Azhar et al., 2017). In addition, the recombinant microorganisms would improve ethanol production from aquatic plants with high hemicellulose content, which can be transformed into a mixture of pentoses and hexoses by saccharification processes (Mishima et al., 2008).

Over recent years, biotechnological advances in the production of bioethanol from aquatic plants have been demonstrated. The use of aquatic and semi-aquatic plants as a renewable energy source presents advantages, such as an absence of competition against food crops for arable land (Mishima et al., 2006, 2008). The elephant ear plant is a lignocellulose source that possesses a rapid growth rate, with a minimal fertilizer needed, and does not compete for arable land, which is attributed to an ideal biofuel feedstock (Low et al., 2011; Miranda et al., 2016). Compared to wood and other lignocellulosic biomass (agro- and forest residue), aquatic and semi-aquatic weeds can be readily hydrolyzed to fermentable sugars and provide an efficient and cost-effective feedstock for renewable energy production, like biofuels. While minimizing the economic and ecological damage caused by their rapid undesired growth can be impressively utilized for the enhanced bioenergy generation (Borah et al., 2016; Rather \& Bhagat, 2021).

\section{Conclusions}

The elephant ear plant, a member of the Arum family (Araceae), is an emergent aquatic and semi-aquatic herbaceous species. The elephant ear plant, considered an invasive species, can be used to produce bioethanol. The physical pretreatment process (hydrothermal and steam explosion) was applied with significant success to enhance the accessibility of 
enzyme and the high sugar concentration achieved. The results revealed that the chemical composition differed across treatments. The steam explosion for $15 \mathrm{~min}(T 2)$ is ideal and resulted in the enhanced fermentable sugars. The fermentation was initiated by infecting the hydrolysate with $1 \%$ S. cerevisiae and maintained at room temperature without oxygen for $120 \mathrm{~h}$. The efficient ethanol percentage was $1.052 \pm 0.03 \mathrm{mg} / \mathrm{mL}$ achieved after the fermentation. The $48 \mathrm{~h}$ of fermentation is an ideal period to produce enhanced ethanol. Thus, the elephant ear plant has the potential to be an efficient feedstock plant for bioethanol production.

Acknowledgements The authors want to extend special thanks to the Faculty of Science, Energy Research Centre, School of Renewable Energy, Maejo University, Chiang Mai, Thailand, for the research facilities to complete this experimental study.

\section{References}

Aswathy, U. S., Sukumaran, R. K., Devi, G. L., Rajasree, K. P., Singhania, R. R., \& Pandey, A. (2010). Bio-ethanol from water hyacinth biomass: An evaluation of enzymatic saccharification strategy. Bioresource Technology, 101(3), 925-930.

Atkins, E. O., \& Williamson, P. (2008). Comparison of four techniques to control elephant ear. Journal of Aquatic Plant Management, 46, 158-162.

Azhar, S., Abdulla, R., Jambo, S., Marbawi, H., Gansau, J., Faik, A., \& Rodrigues, K. (2017). Yeasts in sustainable bioethanol production: A review. Biochemistry and Biophysics Reports, 10, 52-61.

Bhuyar, P., Trejo, M., Dussadee, N., Unpaprom, Y., Ramaraj, R., \& Whangchai, K. (2021). Microalgae cultivation in wastewater effluent from tilapia culture pond for enhanced bioethanol production. Water Science and Technology. https://doi.org/10.2166/wst.2021.194

Bhuyar, P., Sundararaju, S., Math, K. R., Maniam, G. P., \& Govindan, N. (2020). Production of bioethanol from starchy tuber (Amorphophallus commutatus) and antimicrobial activity study of its extracts. African Journal of Biological Sciences, 2(2), 70-76.

Borah, A. J., Singh, S., Goyal, A., \& Moholkar, V. S. (2016). An assessment of the potential of invasive weeds as multiple feedstocks for biofuel production. RSC Advances, 6(52), 47151-47163.

Cruz, M., Pinho, S. C., Mota, R., Almeida, M. F., \& Dias, J. M. (2018). Enzymatic esterification of acid oil from soapstocks obtained in vegetable oil refining: Effect of enzyme concentration. Renewable Energy, $124,165-171$.

Dien, B., Cotta, M., \& Jeffries, T. (2003). Bacteria engineered for fuel ethanol production: Current status. Applied Microbiology and Biotechnology, 63(3), 258-266.

Dubois, M., Gilles, K. A., Hamilton, J. K., Rebers, Pt., \& Smith, F. (1956). Colorimetric method for determination of sugars and related substances. Analytical Chemistry, 28(3), 350-356.

Duden, A., Verweij, P., Kraak, Y., van Beek, L., Wanders, N., Karssenberg, D., Sutanudjaja, E., \& van der Hilst, F. (2021). Hydrological impacts of ethanol-driven sugarcane expansion in Brazil. Journal of Environmental Management, 282, 111942.

Dussadee, N., Reansuwan, K., \& Ramaraj, R. (2014). Potential development of compressed bio-methane gas production from pig farms and elephant grass silage for transportation in Thailand. Bioresource Technology, 155, 438-441.

Dussadee, N., Unpaprom, Y., \& Ramaraj, R. (2016). Grass silage for biogas production. Advances in Silage Production and Utilization, 16, 153.

Frohne, D. \& Pfänder, H. J. (1997). Poisonous plants. A handbook for pharmacists, doctors, toxicologists and biologists. Wissenschaftliche Verlagsgesellschaft $\mathrm{mbH}$.

Gavahian, M., Munekata, P. E., Eş, I., Lorenzo, J. M., Khaneghah, A. M., \& Barba, F. J. (2019). Emerging techniques in bioethanol production: From distillation to waste valorization. Green Chemistry, 21(6), $1171-1185$.

Gupta, G., Gour, V. S., Sharma, P., \& Kothari, S. L. (2017). Acid and enzymatic hydrolysis mediated bioethanol production from biomass of a noxious weed-Parthenium hysterophorus L. Environmental Progress and Sustainable Energy, 36(1), 294-296.

Isarankura-Na-Ayudhya, C., Kongpanpee, T., Prabkate, P., Prachayasittikul, V., \& Tantimongcolwat, T. (2007). Appropriate technology for the bioconversion of water hyacinth (Eichhornia crassipes) to liquid ethanol. EXCLI Journal, 6, 167-176. 
Khammee, P., Unpaprom, Y., Chaichompoo, C., Khonkaen, P., \& Ramaraj, R. (2021). Appropriateness of waste jasmine flower for bioethanol conversion with enzymatic hydrolysis: Sustainable development on green fuel production. 3 Biotech, 11(5), 1-13.

Khammee, P., Ramaraj, R., Whangchai, N., Bhuyar, P., \& Unpaprom, Y. (2020). The immobilization of yeast for fermentation of macroalgae Rhizoclonium sp. for efficient conversion into bioethanol. Biomass Conversion and Biorefinery, 11, 827-835.

Khammee, P., Unpaprom, Y., Buochareon, S., \& Ramaraj, R. (2019). Potential of bioethanol production from marigold temple waste flowers. In Proceeding of the 1st Thailand biorefinery conference, the future of biorefinery for Thailand (Vol. 4, pp. 25-26).

Kikuta, K., Whitney, L. D., \& Parris, G. K. (1938). Seeds and seedlings of the taro, Colocasia esculenta. American Journal of Botany, 25(3), 186-188.

Krenzelok, E., \& Jacobsen, T. (1997). Plant exposures. A national profile of the most common plant genera. Veterinary and human toxicology, 39(4), 248-249.

Kuballa, B., Lugnier, A. A., \& Anton, R. (1981). Study of Dieffenbachia-induced edema in mouse and rat hindpaw: Respective role of oxalate needles and trypsin-like protease. Toxicology and Applied Pharmacology, 58(3), 444-451.

Kumar, S. (2011). Biofuels Make a Comeback Despite Tough Economy. [Online]. Available https://www. enn.com/articles/43174-biofuels-make-a-comeback-despite-tough-economy.

Lin, T. H., Guo, G. L., Hwang, W. S., \& Huang, S. L. (2016). The addition of hydrolyzed rice straw in xylose fermentation by Pichia stipitis to increase bioethanol production at the pilot-scale. Biomass and Bioenergy, 91, 204-209.

Low, T., Booth, C., \& Sheppard, A. (2011). Weedy biofuels: What can be done? Current Opinion in Environmental Sustainability, 3(1-2), 55-59.

Manmai, N., Unpaprom, Y., Ponnusamy, V. K., \& Ramaraj, R. (2020). Bioethanol production from the comparison between optimization of sorghum stalk and sugarcane leaf for sugar production by chemical pretreatment and enzymatic degradation. Fuel, 278, 118262.

Manmai, M., Bautista, K., Unpaprom, Y., \& Ramaraj, R. (2019). Optimization of combined pre-treatments on sugarcane leaves for bioethanol production. Maejo International Jouranal Energy and Environmental Communication, 1(1), 30-39.

Manmai, N., Unpaprom, Y., \& Ramaraj, R. (2020b). Bioethanol production from sunflower stalk: Application of chemical and biological pretreatments by response surface methodology (RSM). Biomass Conversion and Biorefinery. https://doi.org/10.1007/s13399-020-00602-7

Miller, G. L. (1959). Use of dinitrosalicylic acid reagent for determination of reducing sugar. Analytical Chemistry, 31(3), 426-428.

Miranda, A. F., Biswas, B., Ramkumar, N., Singh, R., Kumar, J., James, A., \& Mouradov, A. (2016). Aquatic plant Azolla as the universal feedstock for biofuel production. Biotechnology for Biofuels, 9(1), 1-17.

Mishima, D., Kuniki, M., Sei, K., Soda, S., Ike, M., \& Fujita, M. (2008). Ethanol production from candidate energy crops: Water hyacinth (Eichhornia crassipes) and water lettuce (Pistia stratiotes L.). Bioresource technology, 99(7), 2495-2500.

Mishima, D., Tateda, M., Ike, M., \& Fujita, M. (2006). Comparative study on chemical pretreatments to accelerate enzymatic hydrolysis of aquatic macrophyte biomass used in water purification processes. Bioresource Technology, 97(16), 2166-2172.

Nguyen, T. V. T., Unpaprom, Y., Manmai, N., Whangchai, K., \& Ramaraj, R. (2020). Impact and significance of pretreatment on the fermentable sugar production from low-grade longan fruit wastes for bioethanol production. Biomass Conversion and Biorefinery. https://doi.org/10.1007/s13399-020-00977-7

Nong, H. T. T., Unpaprom, Y., Whangchai, K., Buochareon, S., \& Ramaraj, R. (2020). Assessment of the effects of anaerobic co-digestion of water primrose and cow dung with swine manure on biogas yield and biodegradability. Biomass Conversion and Biorefinery. https://doi.org/10.1007/ s13399-020-01115-z

Olson, J. D. (1989). Measurement of vapor-liquid equilibria by ebulliometry. Fluid Phase Equilibria, 52, 209-218.

Phukoetphim, N., Salakkam, A., Laopaiboon, P., \& Laopaiboon, L. (2017). Kinetic models for batch ethanol production from sweet sorghum juice under normal and high gravity fermentations: Logistic and modified Gompertz models. Journal of Biotechnology, 243, 69-75.

Ramaraj, R., Bhuyar, P., Intarod, K., Sameechaem, N., \& Unpaprom, Y. (2021). Stimulation of natural enzymes for germination of 1 mimosa weeds seeds to productive bioethanol production. 3 Biotech, 11, 307. 
Ramaraj, R., Bhuyar, P., Intarod, K., Sameechaem, N., \& Unpaprom, Y. (2021). Stimulation of natural enzymes for germination of mimosa weed seeds to enhanced bioethanol production. 3 Biotech, 11(6), $1-9$.

Ramaraj, R., \& Dussadee, N. (2015). Biological purification processes for biogas using algae cultures: A review. International Journal of Sustainable and Green Energy, 4(1), 20-32.

Ramaraj, R., Unpaprom, Y., \& Dussadee, N. (2016). Potential evaluation of biogas production and upgrading through algae. International Journal of New Technology and Research, 2(3), 128-133.

Rather, R. A., \& Bhagat, M. (2021). Utilization of Aqueous Weeds for Biofuel Production: Current Status and Future Prospects (pp. 37-57).

IEA. (2019). Renewables 2019. Paris: IEA. Document Number)---. (2020). Global Energy Review 2020. Paris: IEA. Document Number)

Rezania, S., Ponraj, M., Din, M. F. M., \& Songip, A. R. (2014). True Potential of Aquatic plants (Eichhornia crassipes, Pistia stratiotes) in the production of bio-ethanol.

Saengsawang, B., Bhuyar, P., Manmai, N., Ponnusamy, V. K., Ramaraj, R., \& Unpaprom, Y. (2020). The optimization of oil extraction from macroalgae, Rhizoclonium sp. by chemical methods for efficient conversion into biodiesel. Fuel, 274, 117841.

Sharma, B., Larroche, C., \& Dussap, C.-G. (2020). Comprehensive assessment of $2 \mathrm{G}$ bioethanol production. Bioresource technology, 313, 123630.

Sunil, K. R., John, M., Girish, V., \& Girisha, S. T. (2015). A Comparative Study of Bioethanol Production from Aquatic Weeds. INternational Journal of Applied Sciences and Biotechnology, 3(3), 446-451.

Taherzadeh, M. J., \& Karimi, K. (2008). Pretreatment of lignocellulosic wastes to improve ethanol and biogas production: A review. International Journal of Molecular Sciences, 9(9), 1621-1651.

United Nations. (2020). A decade of action to deliver the SDGs. Department of Economic and Social Affairs, Social Inclusion.

Unpaprom, Y., Pimpimol, T., Whangchai, K., \& Ramaraj, R. (2021). Sustainability assessment of water hyacinth with swine dung for biogas production, methane enhancement, and biofertilizer. Biomass Conversion and Biorefinery, 11(3), 849-860.

Van Tran, G., Unpaprom, Y., \& Ramaraj, R. (2020). Methane productivity evaluation of an invasive wetland plant, common reed. Biomass Conversion and Biorefinery, 10, 689-695.

Vu, P. T., Unpaprom, Y., \& Ramaraj, R. (2017). Evaluation of bioethanol production from rice field weed biomass. Emergent Life Sciences Research, 3, 42-49.

Weber, E. (2017). Invasive plant species of the world: a reference guide to environmental weeds. Cabi.

Whangchai, K., Inta, W., Unpaprom, Y., Bhuyar, P., Adoonsook, D., \& Ramaraj, R. (2021). Comparative analysis of fresh and dry free-floating aquatic plant Pistia stratiotes via chemical pretreatment for second-generation (2G) bioethanol production. Bioresource Technology Reports, 14, 100651.

Wiese, M., Kruszewska, S., \& Kolaciński, Z. (1996). Acute poisoning with Diffenbachia picta. Veterinary and Human Toxicology, 38(5), 356-358.

Zhang, Q., Wei, Y., Han, H., \& Weng, C. (2018). Enhancing bioethanol production from water hyacinth by new combined pretreatment methods. Bioresource Technology, 251, 358-363.

Publisher's Note Springer Nature remains neutral with regard to jurisdictional claims in published maps and institutional affiliations. 